\title{
Development of Pneumatic Metering Experimental Test Rig for Groundnut
}

\author{
S. Aravindhn* and M. Saravanakumar \\ Department of Farm machinery \& Power, AEC\& RI, Kumulur, India \\ *Corresponding author
}

\section{A B S T R A C T}

Keywords

Pneumatic metering, Sticky belt, Suction pressure, multipleindexes.

Article Info

Accepted:

15 August 2019 Available Online: 10 September 2019
A laboratory test-rig for groundnut planter was developed for testing and calibrating the pneumatic seed metering mechanism. The experimental test rig mainly consists of main frame, seed hopper, seed metering system, power transmission system and sticky belt system. The metering unit is incorporated with a vertical seed plate held in a vacuum retaining chamber to singulate the seeds. A dial type vacuum gauge was provided in order to record the variation in suction pressure. A sticky belt was used to simulate the field surface during laboratory investigation. Rotational velocity of metering disc, suction pressure and hole size were chosen as the operating parameters. The developed pneumatic metering unit was tested in the laboratory for groundnut seeds based on miss index, multiple index, quality of feed index and mean seed spacing for every treatment combinations. The rotational velocity of metering disc and forward speed of grease coated belt was varied with the help of variable drive controller with necessary motor arrangements.

\section{Introduction}

Seed sowing is one of precise operation, which requires the proper placement of seeds in optimum living area. The sowing operation needs a high degree of precision to increase the efficiency of the inputs and reduce the losses. Sowing of the required quantity of seeds at proper depth and uniform spacing throughout the operation can only be possible with the use of suitable metering mechanism.
In groundnut cultivation the main condition for high yield depends on seeds being sown in optimum living area.

Precision planting is the concept of placement of single seeds in a row at equidistant from each other. The application of pneumatics in the existing vertical plate metering has rapidly increasing the seeding performance. Thus for increasing the planting efficiency, metering unit of pneumatic single seed planter had 
better be close enough to maintain the seed to seed distance within the row without any physical damage to the seeds (Srivastava et al.,1993). Adoption of vacuum planters with flat discs has increased, as they are less sensitive to variations in seed sizes and shapes, thereby providing more consistent plant ability with lesser need to adjust the vacuum pressure (Nielson et al., 1994).

The main key component of pneumatic planters is its metering mechanism, which directly affects the uniform distribution of seeds. The first precision planters developed was horizontal plate metering was very popular but problem occurred with higher seed damage, missing and multiple drops. In order to overcome those problems vertical and inclined plate planters have developed and used for sowing. The usage of mechanical planter for bold seeds like maize, sorghum and groundnut cause much damage to the delicate epidermis, which also hampers germination in the field condition. In additions, the devices of mechanical seed metering used in conventional drills are not capable of operating at high travel speed (Jayan and Kumar, 2004).

A wide variety of measures has been used to quantify seed drill performance with regard to seed spacing (Jasa et al., 1982) and (Kachman and Smith, 1995).Evaluation of developed pneumatic metering mechanism in field conditions seems to be a crucial method of assessing the performance due to external environmental conditions. The external weather conditions hamper the viability of seeds during germination, which reflect negative impact on performance of metering mechanism. So to overcome the constraints a sticky belt setup was used under laboratory conditions to assess the performance of metering mechanism. The evaluation of metering unit based on misses, multiples and quality index yielded the best results in grease coated sticky belt when compared to other methods (Bracy and parish, 1998) and (Yasir et al., 2012).

\section{Materials and Methods}

\section{Determination of physical properties of groundnut seeds}

The physical properties of the seed is one of the important criteria to be considered in defining a pneumatic planter. The physical properties such as bulk density and angle of repose were measured based on the standard procedure. The major and minor diameters of seeds were determined by randomly selecting 30 seeds from a lot. The dimension was measured using a digital vernier caliper with an accuracy of $0.02 \mathrm{~mm}$. The single seed weight is important to determine the range of vacuum pressure in the metering chamber. The single seed weight was measured with the help of electronic weighing balance with an accuracy of $0.001 \mathrm{~g}$. These values were computed and results are furnished in table 1.

\section{Development of pneumatic metering mechanism}

A pneumatic metering mechanism was developed which uses negative pressure for seed singulation. A power operated centrifugal aspirator was used to create vacuum pressure in the metering mechanism.

The seed metering system in the test rig consists of an aspirator, a pressure chamber, a metering disc and a scraper to remove seed carried by the metering disc. The pressure chamber was fabricated using a circular PVC tube of $200 \mathrm{~mm}$ diameter and $150 \mathrm{~mm}$ length. A $200 \mathrm{~mm}$ diameter circular acrylic sheet was cut and firmly fitted on one end of PVC tube with necessary sealing arrangement. Another disc made of acrylic sheet of size $200 \mathrm{~mm}$ diameter was attached at a distance of $80 \mathrm{~mm}$ 
from the first disc on a small groove of $5 \mathrm{~mm}$ thick made on the inner side of PVC tube to locate the second disc. The first disc was held stationary and the second disc was rotated to meter the seeds from seed chamber. The space between the two discs was completely sealed without air leakage to act as pressure chamber. 15 numbers of holes based on minor diameter of seeds were drilled equidistantly on the rotating disc which carries seeds from seed chamber. A seed chamber of a quadrant of circle $90 \mathrm{~mm}$ radius was fabricated using 1 $\mathrm{mm}$ thick acrylic sheet which provided room for seeds receiving from the seed hopper. It was made of $1 \mathrm{~mm}$ thick MS sheet of length $64 \mathrm{~mm}$ and height $60 \mathrm{~mm}$. The sheet was bent into circular ring like structure to be perfectly fitted inside the PVC tube in front of metering disc. An L shaped structure was fabricated out of $1.3 \mathrm{~mm}$ MS sheet was perfectly welded in the ring-shaped sheet. On the periphery of a circular quadrant a hole of size $25 \mathrm{~mm}$ diameter was made to allow seeds from the seed tube of the hopper. The aspirator was used to create negative pressure in the pressure chamber of the seed metering unit where the seeds are picked up at the holes of seed metering disc. The aspirator was connected to the pressure chamber with suitable hose and accessories. The metering chamber was fabricated as shown in fig 1 .

\section{Construction of a Test rig}

A test rig was developed to investigate the influence of selected variables and to select the optimum parameter for achieving the best performance of pneumatic metering mechanism. The experimental test rig mainly consists of main frame, seed hopper, seed metering system, power transmission system and sticky belt system as shown in fig 2.1. The main frame of the experimental test rig was used to assemble the seed hopper, seed metering system and power transmission system. A main frame of size 1000 x $450 \mathrm{~mm}$ was fabricated in rectangular shape using $50 \mathrm{x}$ $50 \times 2.5 \mathrm{~mm}$ MS "L" angle to fit the metering mechanism and seed hopper. A seed hopper of trapezoidal shape was fabricated using $1.5 \mathrm{~mm}$ thick MS sheet with 250 x $130 \mathrm{~mm}$ cross section at the top and $50 \times 25 \mathrm{~mm}$ cross section at the bottom. The power to the metering disc was transmitted using belt pulley system from a 3 phase $2.5 \mathrm{hp}$ induction motor which is supported in main frame of sticky belt system. Another rectangular frame of cross section $2800 \mathrm{x} 600 \mathrm{~mm}$ was fabricated using 50 × 50 × $2.5 \mathrm{~mm}$ MS "L" angle in order to accommodate sticky belt system. Two cylindrical rollers of $300 \mathrm{~mm}$ diameter supported by pillow block bearings were separated at a distance of $2600 \mathrm{~mm}$ were fastened to the frame with bolts and nuts at two ends of the frame. A belt of width 300 mm fully smeared with grease was connected between these two rollers to form an endless belt. Out of these two rollers one roller acted as drive and other acted as driven. The electric motor was fitted to the main frame using necessary supports. The variable drive controller facilitated to vary the speed of the sticky belt which correlated the variation of forward speed of the operation.

\section{Experimental procedure}

The experiments were carried out on groundnut seeds. The sticky belt rollers were driven by a $5 \mathrm{hp}$ motor whose speed was varied to control the speed on grease belt. The speed of the greased belt was controlled by a speed regulator of the variable speed drive. The greased belt was driven at the speed of $1.8 \mathrm{~km}$ $\mathrm{h}^{-1}$. The metering disc was rotated at three levels of 16, 24 and $34 \mathrm{rpm}$ corresponding to0.14, 0.24 and $0.34 \mathrm{~ms}^{-1}$. The speed of the metering disc was controlled by variable speed drive according to the selected levels of variables. The seeds were allowed to fall on the greased belt over a length for one full revolution of belt and the readings were noted 
for $160 \mathrm{~cm}$ for every treatment combination. The spacing between the seeds was measured on the greased belt for using a $3 \mathrm{~m}$ measuring tape. The experiment was replicated three times for each combination of selected variables.

\section{Performance analysis of metering mechanism}

The performance of developed metering mechanism was evaluated based on observed spacing on greased belt with that of theoretical spacing of $10 \mathrm{~cm}$. The performance measure based on multiple index, miss index and quality of feed index and mean spacing was a proper method of summarizing distribution of seed spacing for precision planters (Kachman and smith, 1995).Miss index (MISI) is the percentage of seed spacing's that are greater than 1.5 times the theoretical seed spacing and indicates the percentage of missed seed locations or skips. Multiple index (MULI) is the percentage of spacing that are less than 0.5 times than the theoretical seed spacing. Quality of feeding index (QFI) is the percentage of seed spacing that is more than half but no more than 1.5 times the theoretical spacing and indicates the percentages of single seed drops. The calculation formulas for MISI, MULI and QFI are as follows.

Miss index

Multiple index $\left(\mathrm{I}_{\text {mult }}\right) I_{\text {mult }}=\frac{n_{2}}{N}$

Quality of feed index $\mathrm{I}_{\mathrm{QFI}}=100-\left(\mathrm{I}_{\text {miss }}+\mathrm{I}\right.$ multi)

$$
\begin{aligned}
& \text { Where, } \\
& \mathrm{n}_{1} \text { is number of spacing }>1.5 \mathrm{~S}, \\
& \mathrm{n}_{2} \text { is number of spacing } \leq 0.5 \mathrm{~S}
\end{aligned}
$$

$\mathrm{N}$ is total number of measured spacing.

\section{Results and Discussion}

The physical properties for groundnut seeds (VRI 7)were measured and presented in table 1. The major and minor diameter of seeds was measured as 11.50 and $5.5 \mathrm{~mm}$. The diameter of seeds was taken into consideration to ascertain diameter of holes in the metering disc.

The single seed weight of groundnut seed was $0.43 \mathrm{~g}$ which was used to calculate the range of required suction pressure. The bulk density and angle of repose was calculated as $0.65 \mathrm{~g} / \mathrm{cc}$ and $29.8^{\circ}$ which were used to calculate the capacity and inclination of seed hopper. The angle of repose recorded for maize was 30 degree.

\section{Performance of metering mechanism on seed spacing}

The distribution of seeds on the greased belt based on evaluation parameters was shown in fig 3 .

The developed metering mechanism was evaluated in terms of maximum quality of feed index; desired spacing between the hills, minimum missing, and multiple index per cent.

The highest value of quality of feed index was obtained as95.53 per cent. The minimum value of miss and multiple index was registered as 6.67 and 0 per cent.

The mean spacing on distribution of seeds was obtained as $9.96 \mathrm{~cm}$, which was close to theoretical seed spacing of groundnut seeds. Similar results were reported by (Anantacher, 2007) for peanut varieties and (Barut and ozmerzi, 2004) for wheat crops. The experimental test rig was developed for pneumatic metering mechanism for groundnut seeds and evaluated in the laboratory on 
grease coated belt. The results revealed that decreases the performance of metering increasing the velocity of metering disc causes the quality of feed index to decrease which mechanism.

Fig.1 Pneumatic metering mechanism.

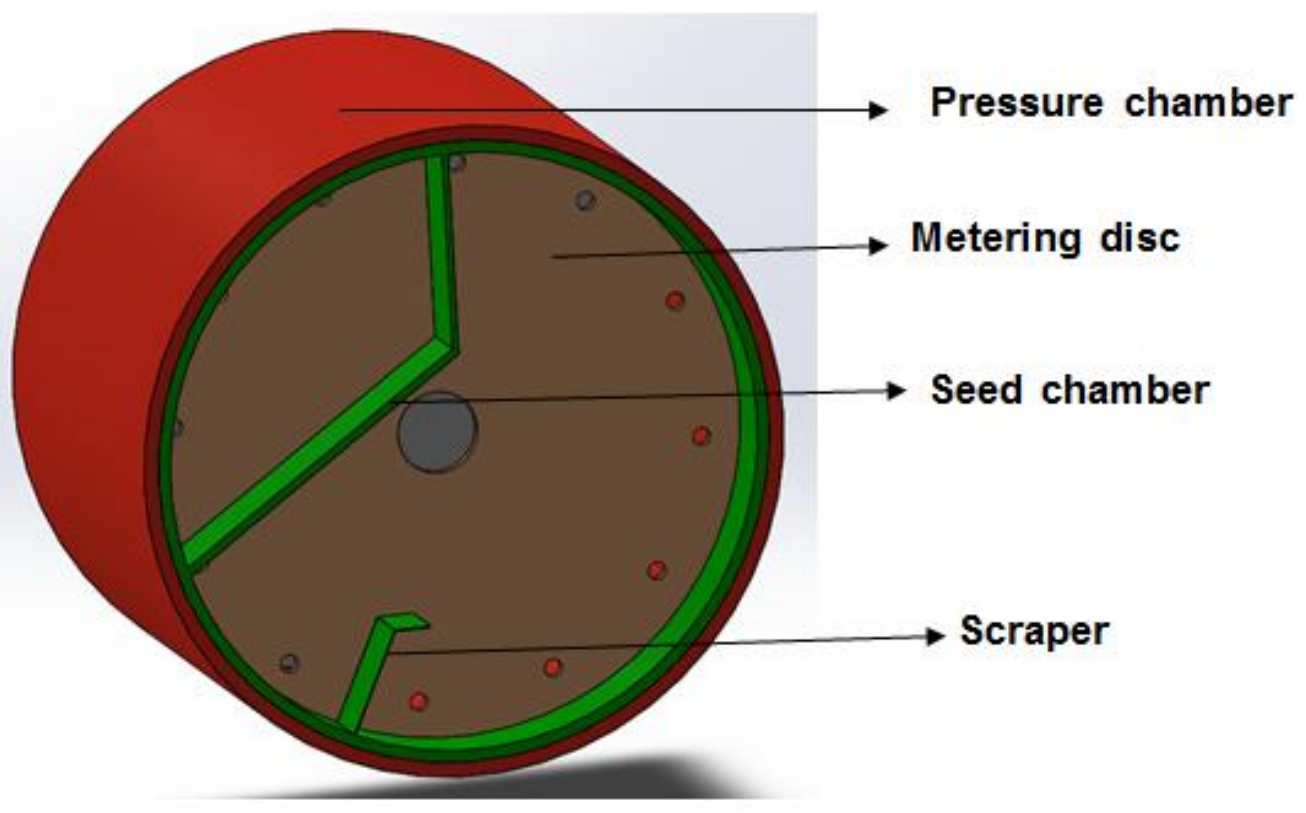

Fig.2 Top view of test rig

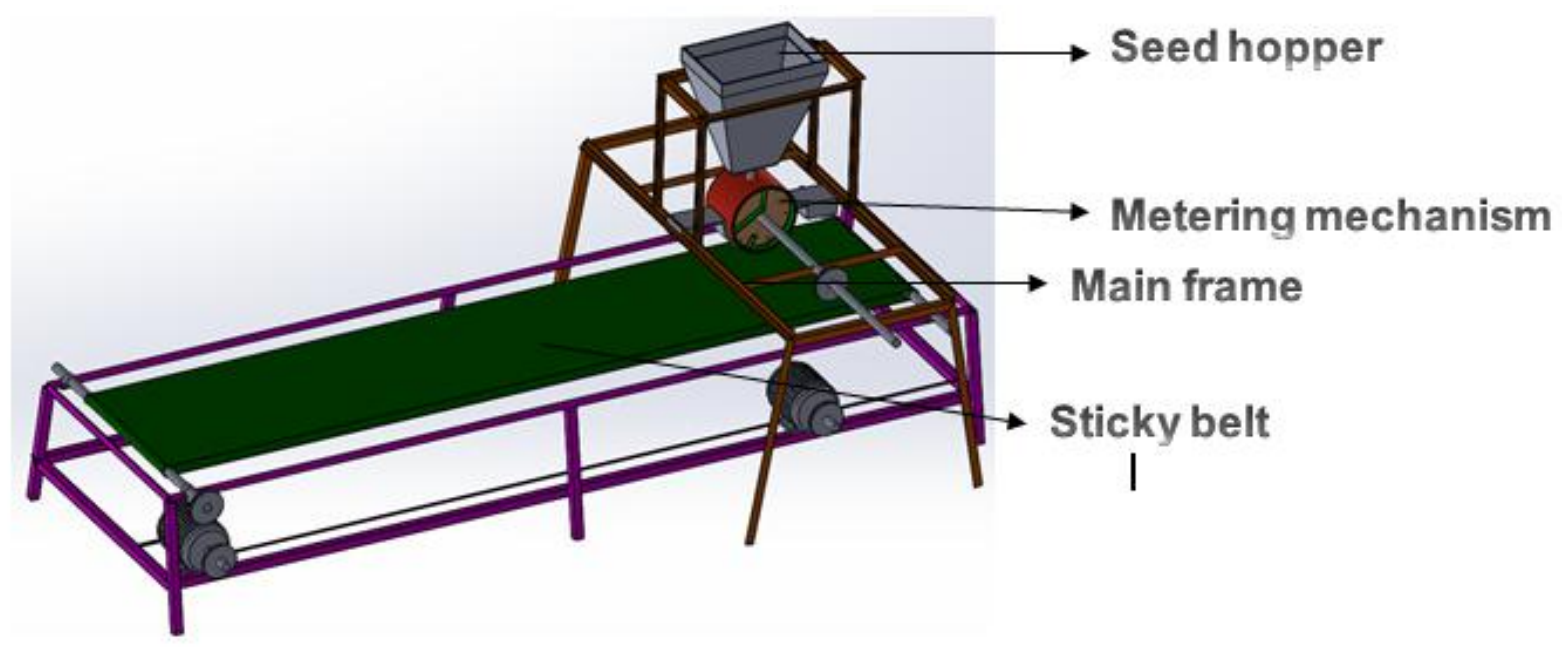


Fig.2.1 Experimental test rig

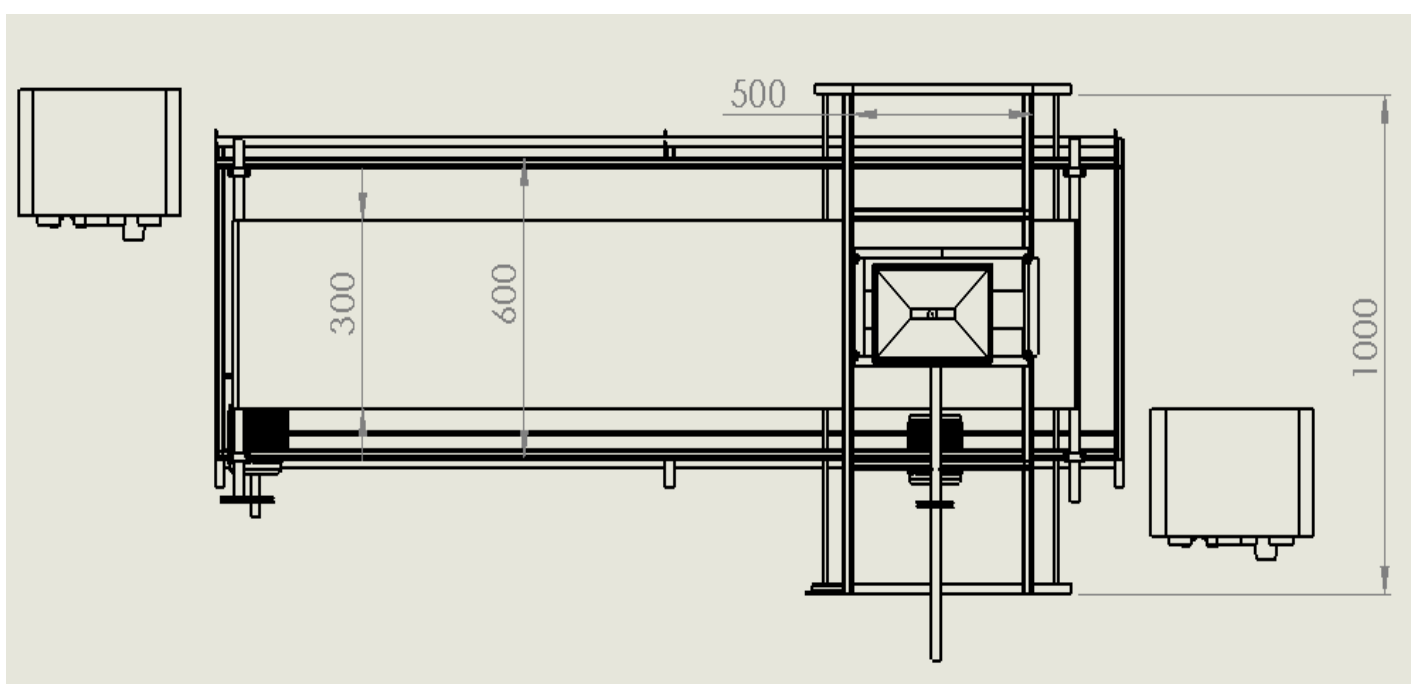

Fig.3 Performance indices of pneumatic metering mechanism.

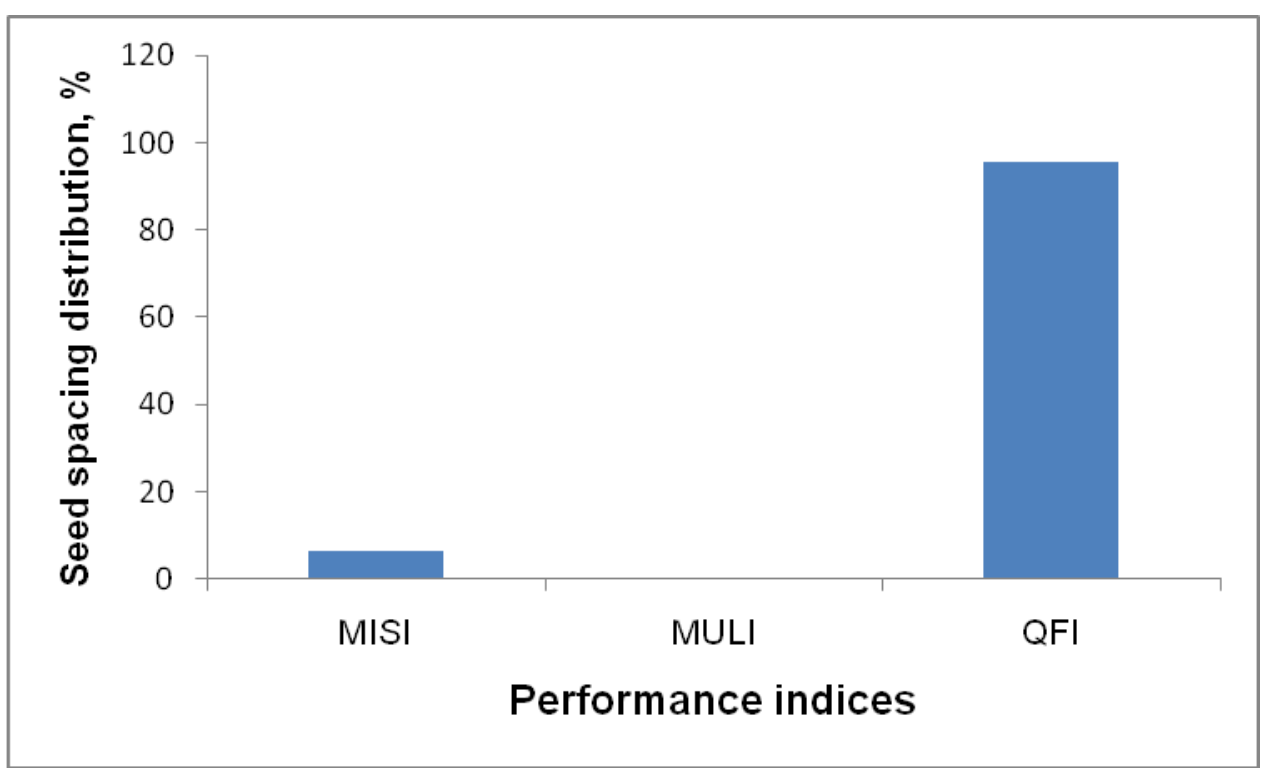

Table.1 Seed properties of groundnut

\begin{tabular}{|r|l|c|}
\hline SI. No & Properties & Values \\
\hline $\mathbf{1}$ & Physical dimensions & \multicolumn{2}{|c|}{} \\
\hline & a) Major diameter, $\mathrm{mm}$ & 11.50 \\
\cline { 2 - 3 } & b) Minor diameter, mm & 5.50 \\
\hline $\mathbf{2}$ & Single seed weight, g & 0.43 \\
\hline $\mathbf{3}$ & ${\text { Bulk density, } \mathrm{gm} \mathrm{cm}^{-3}}^{-3}$ & 0.65 \\
\hline $\mathbf{4}$ & Angle of repose, $^{\mathrm{o}}$ & 29.8 \\
\hline
\end{tabular}




\section{References}

Anantachar M. 2007. Investigations on design \& operational para-meters of multi crops for selected crops of north Karnataka,Dept of Farm Power \& Machinery, UAS, Dharward.

Bracy, R. P., R. L. Parish, and J. E. McCoy. 1998. Precision seeder uniformity varies with theoretical spacing. ASAE Paper No. 981095. ASAE, St. Joseph, M.

Jasa, P. J., and E. C. Dickey. 1982. Tillage factors affecting corn seed spacing. Transactions of the ASAE 25(6): 1516-1519.

Jayan, P.R., and Kumar, V.J.F. 2004. Planter design in relation to the physical properties of seeds. Journal of Tropical Agriculture. 42(1-2): 69-71.

Kachman, S.D. and Smith J. A., 1995, Alternative measures of accuracy in plant spacing for planters using single seed metering Transactions of the
ASAE, 38(2): 379-387.

Karayel D; Barut Z B; Ozmerzi A (2004). Mathematical modeling of vacuum pressure on a precision seeder. Biosystems Engineering 87(4), 437 444.

Liao, Q. X., J. B. Li, and G. L Qin. 2009. Experiment of pneumatic precision metering device for rapeseed. Transactions of the Chinese Society of Agricultural Machinery, 40(8): 44-48.

Nielsen, R.L. Planting speed effects on stand establishment and grain yield of corn. Purdue: Purdue University, 1994. 22p.

Srivastava A K; Goering C E; Rohrbach R P (1993). Engineering Principals of Agricultural Machines. ASAE Textbook Number 6. Pamela De VoreHansen, Editor Information Publishing Group, USA. pp: (235).

Yasir, S.H., Q.X. Liao, J.J. Yu and D. He, 2012. Design and test of a pneumatic precision metering device for wheat. Agric. Eng. Int. CIGR J., 14(1): 16-25.

\section{How to cite this article:}

Aravindhn, S. and Dr. Saravanakumar, M. 2019. Development of Pneumatic Metering Experimental Test Rig for Groundnut. Int.J.Curr.Microbiol.App.Sci. 8(09): 1397-1403. doi: https://doi.org/10.20546/ijcmas.2019.809.160 